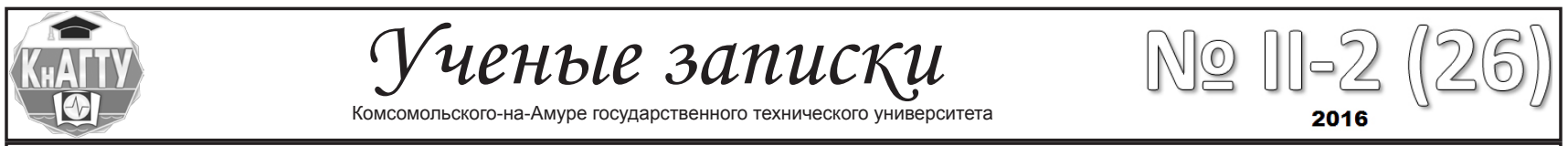

Макаренко С. В., Мешков А. С.

S. V. Makarenko, A. S. Meshkov

ИНСТРУМЕНТЫ РАННЕЙ ПРОФОРИЕНТАЦИИ

В КОМСОМОЛЬСКОМ-НА-АМУРЕ ГОСУДАРСТВЕННОМ

ТЕХНИЧЕСКОМ УНИВЕРСИТЕТЕ

\title{
TOOLS OF OCCUPATIONAL GUIDANCE IN EARLY STAGES IN KOMSOMOLSK-ON-AMUR STATE TECHNICAL UNIVERSITY
}

Макаренко Сергей Валерьевич - начальник отдела организации профориентации и рекламы Комсомольского-на-Амуре государственного технического университета (Россия, г. Комсомольск-наАмуре); 681013, Комсомольск-на-Амуре, пр. Ленина, 27. E-mail: nabor@knastu.ru.

Mr. Makarenko Sergey V. - Head of the Organization of vocational guidance and promotion Department, Komsomolsk-on-Amur State Technical University (Russia, Komsomolsk-on-Amur); 681013, Komsomolskon-Amur, 27, Lenin Str. E-mail: nabor@knastu.ru

Мешков Александр Сергеевич - кандидат технических наук, заместитель директора Технопарка Комсомольского-на-Амуре государственного технического университета (Россия, г. Комсомольск-наАмуре); 681013, Комсомольск-на-Амуре, пр. Ленина, 27. E-mail: meshkovlive@gmail.com.

Mr. Meshkov Alexandr S. - Ph.D., deputy director of the Technopark of Komsomolsk-on-Amur State Technical University (Russia, Komsomolsk-on-Amur); 681013, Komsomolsk-on-Amur, 27, Lenin Str. E-mail: meshkovlive@gmail.com.

Аннотация. В статье рассмотрены инструменты профессиональной ориентации школьников, используемые в работе Комсомольского-на-Амуре государственного технического университета в 20132016 гг.

Summary. The article deals with vocational guidance tools for students used in Komsomolsk- on-Amur State Technical University in 2013-2016.

Ключевые слова: профориентация, каникулярная школа, информационный десант, абитуриент.

Key words: vocational guidance, school for holidays, informing troops, applicant for entry.

УДК 378.18:316.334.2

В апреле 2015 г. в ходе прямой линии с Владимиром Путиным, отвечая на вопрос предпринимателя Сергея Партина о проблеме ранней профориентации, Президент России особо отметил, что подготовка профессиональных кадров в сфере производства является одним из ключевых элементов роста экономики. «Лучше бы начинать эту профориентацию на самой ранней стадии, ещё в школе», - признал Владимир Путин.

В Комсомольском-на-Амуре государственном техническом университете уже на протяжении нескольких лет выстраивается система ранней профориентации (профориентации школьников), и можно уверенно заявить, что такая работа является одним из важнейших направлений деятельности КнАГТУ. В настоящее время разработаны и применяются различные инструменты профориентационной работы, нацеленной на повышение интереса школьников в первую очередь именно к инженерным профессиям, которые сейчас особенно востребованы в городе и регионе. Специфика профориентационной работы вуза ещё и в том, что особый акцент делается на те специальности и направления, по которым реализуются образовательные программы именно в нашем университете. 
Макаренко С. В., Мешков А. С.

ИНСТРУМЕНТЫ РАННЕЙ ПРОФОРИЕНТАЦИИ В КОМСОМОЛЬСКОМ-НА-АМУРЕ

ГОСУДАРСТВЕННОМ ТЕХНИЧЕСКОМ УНИВЕРСИТЕТЕ

В профориентационной работе со школьниками вузом используются следующие инструменты:

- проведение массовых мероприятий для школьников;

- организация образовательных и конкурсных проектов.

Массовые мероприятия направлены на привлечение интереса учащихся образовательных учреждений среднего общего образования как к профессиям инженерной направленности, так и к университету в целом. В число таких мероприятий входят: экскурсии по лабораториям факультетов и технопарка КнАГТУ, дни открытых дверей, информационные десанты, мероприятия познавательно-развлекательного характера.

Самая традиционная и опробованная форма ознакомления школьников с работой университета - экскурсия, в ходе которой учащиеся школ имеют возможность наблюдать и даже самостоятельно принимать участие в выполнении учебных и научных экспериментальных работ, получить в наглядной форме информацию о методах обучения и современном оборудовании, используемом в учебном процессе. Экскурсии для школ в КнАГТУ проводятся уже на протяжении многих лет. Но в последние годы эта работа систематизирована, посещение университета школьниками больше не носит спонтанный характер, когда инициатива проведения экскурсии исходила, как правило, от отдельных школ. В настоящее время ученики всех школ в соответствии с согласованным графиком могут посетить лаборатории университета. Экскурсии проводятся для школьников разных возрастных групп с 4 по 11 классы. В зависимости от возраста экскурсантов разработаны и маршруты экскурсий. Также для ребят разного возраста в адаптированной форме излагается и информация о процессах, которые они наблюдают в лабораториях. Особый интерес у школьников младшего возраста вызывает посещение центра робототехники, лаборатории быстрого прототипирования и 3D-печати, лаборатории технологии самолётостроения и уникальной гидротехнической лаборатории «Опытовый бассейн КнАГТУ». Учащиеся старших классов также с интересом посещают лаборатории разрушающего контроля материалов, материаловедения, химических технологий, архитектуры и дизайна, другие лаборатории и исследовательские центры университета. Особым интересом у посетителей всех возрастов пользуется также кафедра военной подготовки. За одну экскурсию ребята посещают, как правило, две - три лаборатории. Общая продолжительность экскурсии - от 40 минут для младших школьников до 1 часа для старшеклассников.

День открытых дверей - это также традиционная форма работы со школьниками. В настоящее время в КнАГТУ формат данного мероприятия включает, помимо информационной встречи участников с руководством университета и посещения отдельных факультетов, обязательную интерактивную выставку. В рамках такой выставки каждый факультет или институт организует собственную экспозицию с элементами научного шоу, на которой демонстрируются в яркой и доступной форме различные разработки или учебное оборудование: квадрокоптер, симулятор управления летательным аппаратом, катушка Тесла в действии, установка для исследования электродуговых разрядов, роботизированная тележка, тепловизор, система стабилизации грузов, занимательные химические опыты, различные геодезические приборы, сварочный тренажёр, микроскоп и ещё много интересного. Обязательной составляющей мероприятия является и развлекательная программа от творческих студенческих коллективов университета, что демонстрирует посетителям мероприятия доступность и возможность в полной мере во время обучения в университете заниматься творчеством и другой внеучебной деятельностью.

С 2016 г. КнАГТУ применяет такой инструмент ранней профориентации, как информационный десант. Это мероприятие проводится для школьников из удалённых от Комсомольска-на-Амуре населённых пунктов, которые не имеют возможности посетить мероприятия, проводимые в вузе. Формат информационного десанта схож с форматом дня открытых дверей с той лишь разницей, что он проводится в выездной форме. В апреле 2016 г. инфор- 
мационные десанты прошли на базе МОУ СОШ № 1 г. Советская Гавань и филиала КнАГТУ в п. Ванино. Учащиеся этих населённых пунктов также смогли посетить интерактивные экспозиции факультетов и институтов университета и получить исчерпывающую информацию о возможностях обучения в университете, об исследованиях, которыми занимаются учёные вуза от ответственного секретаря приёмной комиссии и других представителей КнАГТУ, прибывших в составе десанта.

С 2014 г. Комсомольский-на-Амуре государственный технический университет организует и проводит Открытый фестиваль технического творчества «Технофест». Целями проведения фестиваля являются выявление талантливой творческой молодёжи, развитие образовательных компетенций и организаторских способностей обучающихся, популяризация современных научных школ и направлений. Мероприятия фестиваля обеспечивают решение следующих задач:

- развитие и популяризация технического творчества среди школьников и студенческой молодёжи;

- ранняя профессиональная ориентация детей на инженерные и рабочие специальности;

- оценка творческого потенциала молодёжи и вовлечение её в научную среду;

- формирование новых знаний, умений и компетенций обучающихся в области инновационных технологий, радиоэлектроники, робототехники, моделирования и программирования.

Участниками фестиваля являются обучающиеся образовательных организаций основного общего, среднего общего, дополнительного образования, среднего и высшего профессионального образования.

Перечень мероприятий фестиваля в 2016 г. включает:

- открытые соревнования по робототехнике по различным направлениям;

- открытые соревнования автомоделей в номинациях: дрифт, триал, шорт-трек;

- открытые краевые соревнования по судомодельному спорту среди школьников;

- открытое Первенство Хабаровского края по трассовому автомоделизму; юниоров.

- Первенство Хабаровского края по авиационным кордовым моделям среди юношей и

География участников фестиваля постоянно расширяется. Если в 2014 г. в Технофесте приняли участие около 75 человек из Хабаровского края, то в 2015 г. их было уже более 200 из Хабаровского края, Амурской и Еврейской автономной областей, а также из Китайской народной республики.

В апреле 2016 г. в п. Ванино прошёл первый межрайонный фестиваль технического творчества «Технокон», организатором которого выступил филиал Комсомольского-наАмуре государственного технического университета. Участниками фестиваля стали школьники из Ванинского и Советско-Гаванского районов, среди которых проводились соревнования по робототехнике в младшей и старшей группах.

Ежегодно в канун нового года в КнАГТУ проводится «Ректорская ёлка» - праздничное мероприятие для лучших одиннадцатиклассников Комсомольска-на-Амуре (см. рис. 1). В программе масштабного события - выставка инновационных разработок, выполненных школьниками и студентами, праздничное интерактивное шоу с элементами team building и необычные праздничные сюрпризы.

\section{Образовательные и конкурсные проекты.}

В КнАГТУ с 2013 г. Ресурсным центром Технопарка реализуется уникальный образовательный проект - Каникулярная школа «Технологии будущего», - нацеленный на популяризацию среди молодёжи инженерных профессий, инновационного предпринимательства и научно-технического творчества. В течение всего учебного года во время каникул школьни- 
Макаренко С. В., Мешков А. С.

ИНСТРУМЕНТЫ РАННЕЙ ПРОФОРИЕНТАЦИИ В КОМСОМОЛЬСКОМ-НА-АМУРЕ ГОСУДАРСТВЕННОМ ТЕХНИЧЕСКОМ УНИВЕРСИТЕТЕ

ки 5-11-х классов проходят обучение в лабораториях КнАГТУ по ряду технических направлений.

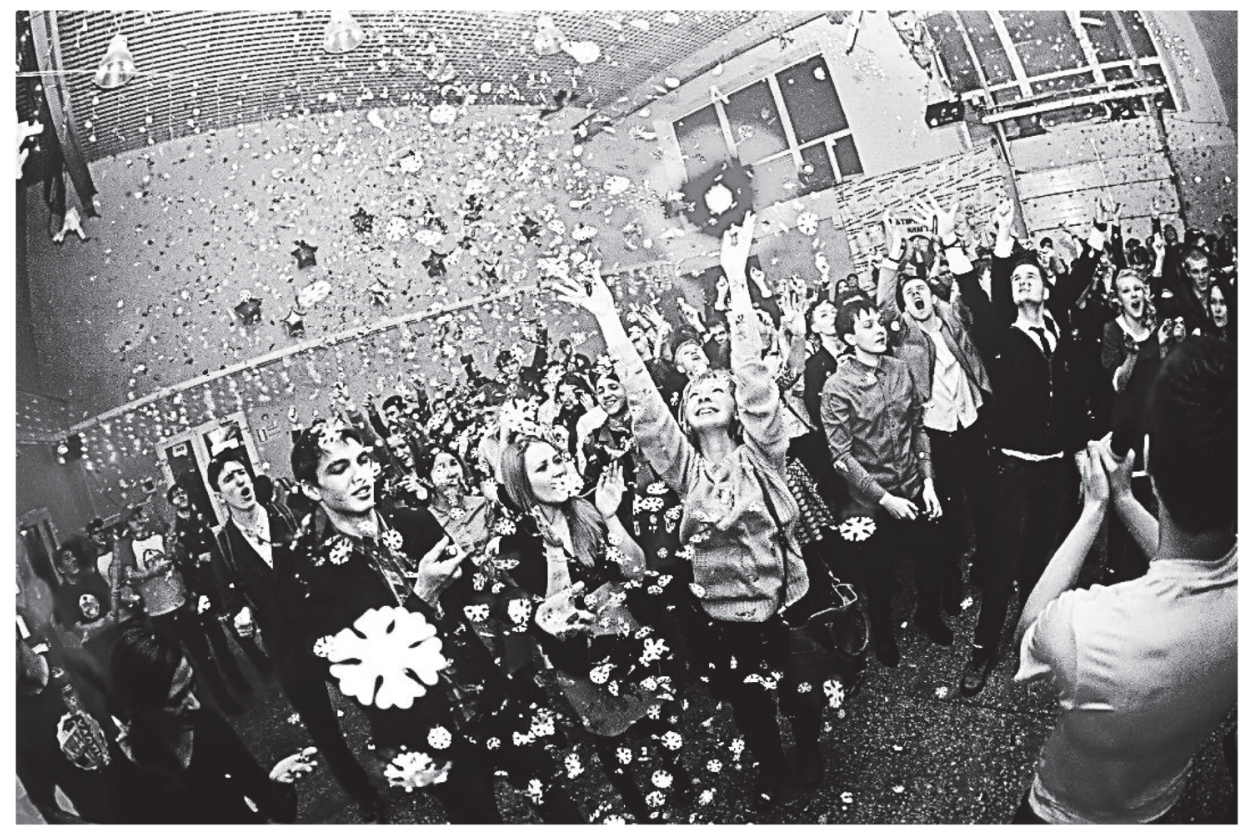

Рис. 1. «Ректорская ёлка» КнАГТУ для лучших одиннадцатиклассников города

Материально-техническая база школы «Технологии будущего» имеет развитую инфраструктуру, а также оснащена современным оборудованием. Производственные площадки приспособлены к каждому направлению центров обучения:

- Центр цифрового производства Технопарка КнАГТУ: лаборатория станков с ЧПУ, лаборатория САПР, лаборатория быстрого прототипирования и промышленного дизайна;

- Центр автоматизации Технопарка КнАГТУ: учебный центр технологий National Instruments, лаборатория быстрого прототипирования печатных плат;

- Центр коллективного пользования научно-исследовательского оборудования «Новые материалы и технологии» КнАГТУ;

- Центр коллективного пользования «Океанотехника» КнАГТУ: опытовый бассейн, модельный участок;

- Центр робототехники и моделирования (см. рис. 2).

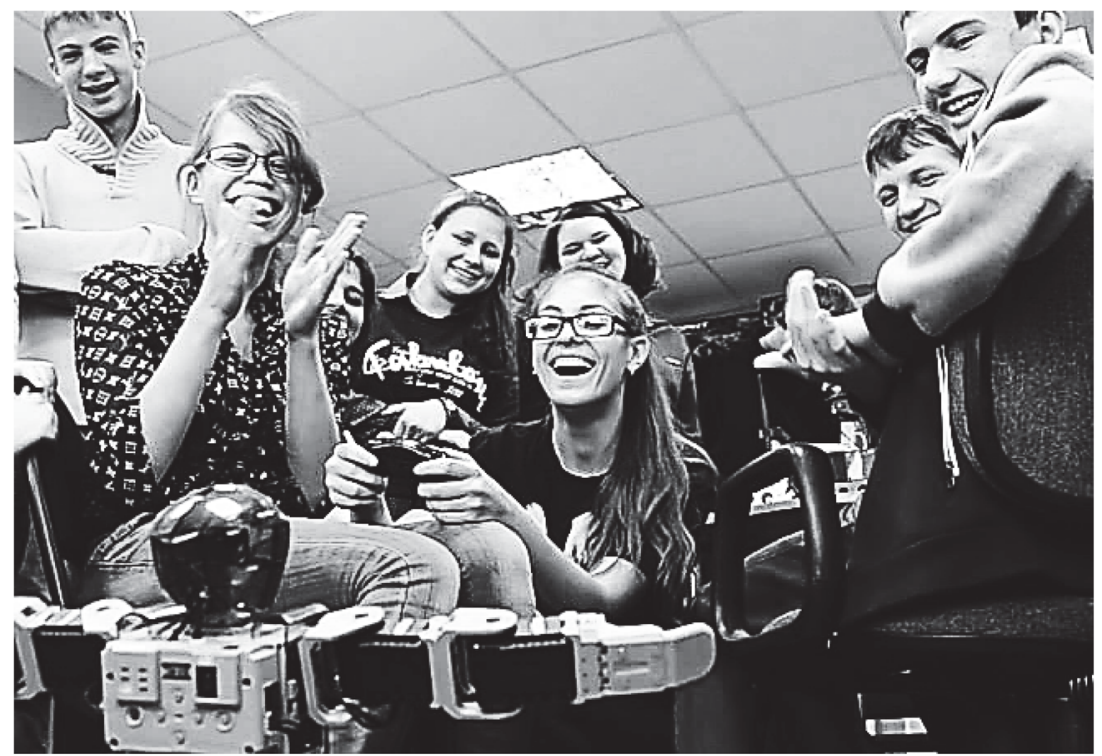

Рис. 2. Занятия в Каникулярной школе. Направление «Робототехника» 
Основные направления школы «Технологии будущего»:

- Школа кадастра и строительства: землеустройство и кадастры, строительство, дизайн архитектурной среды, геодезия;

- Школа инновационных технологий: трёхмерное моделирование, технологии быстрого прототипирования, станки с ЧПУ, основы материаловедения; робототехника и автоматика; ТРИЗ;

- Школа программиста: разработка мобильных приложений, разработка веб-сайтов,

- Школа морских технологий;

- Школа технологий самолетостроения;

- Школа электротехники;

- Школа химических технологий;

- Школа экономиста: тайм-менеджмент и основы предпринимательства;

- Школа рекламы и PR-технологий;

- Школа переводчика;

- Школа военного дела;

- Школа криминалиста.

На сегодняшний день каникулярная школа «Технологии будущего» - это большой образовательный проект, участие в котором принимают более 30 образовательных учреждений и организаций и в котором, в общей сложности, приняло участие более 1500 школьников по всему Хабаровскому краю (см. рис. 3). В 2016 г. проект «Каникулярная школа КнАГТУ» победил в конкурсе «Профориентация школьников под задачи Национальной технологической инициативы», организованном направлением «Молодые профессионалы» Агентства стратегических инициатив (АСИ).

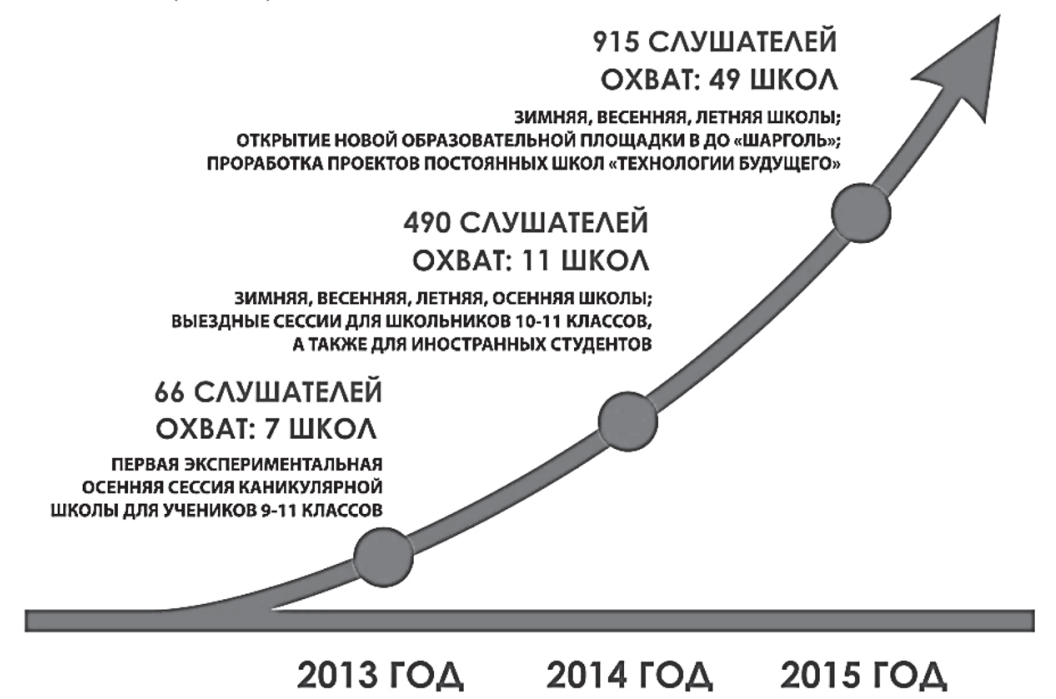

Рис. 3. Динамика роста количества участников «Каникулярной школы»

Ежегодно в университете организуется и проводится более 20 олимпиад и конкурсов различного уровня для старшеклассников, принимая участие в которых школьники не только могут более глубоко погрузиться в основы возможно будущей профессии, но и заработать дополнительные баллы, которые при поступлении в КнАГТУ добавляются к баллам, полученным по результатам ЕГЭ. Таким образом, сумма конкурсных баллов у победителей и призёров олимпиад и конкурсов увеличивается, что увеличивает и их шансы поступления на желаемое направление обучения.

Отдельно стоит отметить конкурс научно-технических проектов «Юный инженер», который организует с 2015 г. Технопарк КнАГТУ (см. рис. 4). Конкурс направлен на развитие условий для научно-технической самореализации, поддержки и поощрения талантливых школьников и студентов. В ходе конкурса юные инженеры проходят обучение в Технопарке 
Макаренко С. В., Мешков А. С.

ИНСТРУМЕНТЫ РАННЕЙ ПРОФОРИЕНТАЦИИ В КОМСОМОЛЬСКОМ-НА-АМУРЕ ГОСУДАРСТВЕННОМ ТЕХНИЧЕСКОМ УНИВЕРСИТЕТЕ

под руководством кураторов от университета, благодаря которому разрабатывают и представляют на суд жюри в финале свои интересные научно-технические проекты. Участники конкурса не только погружаются в научную деятельность, но и осознают, что наука и изобретательство - это интересно и увлекательно.

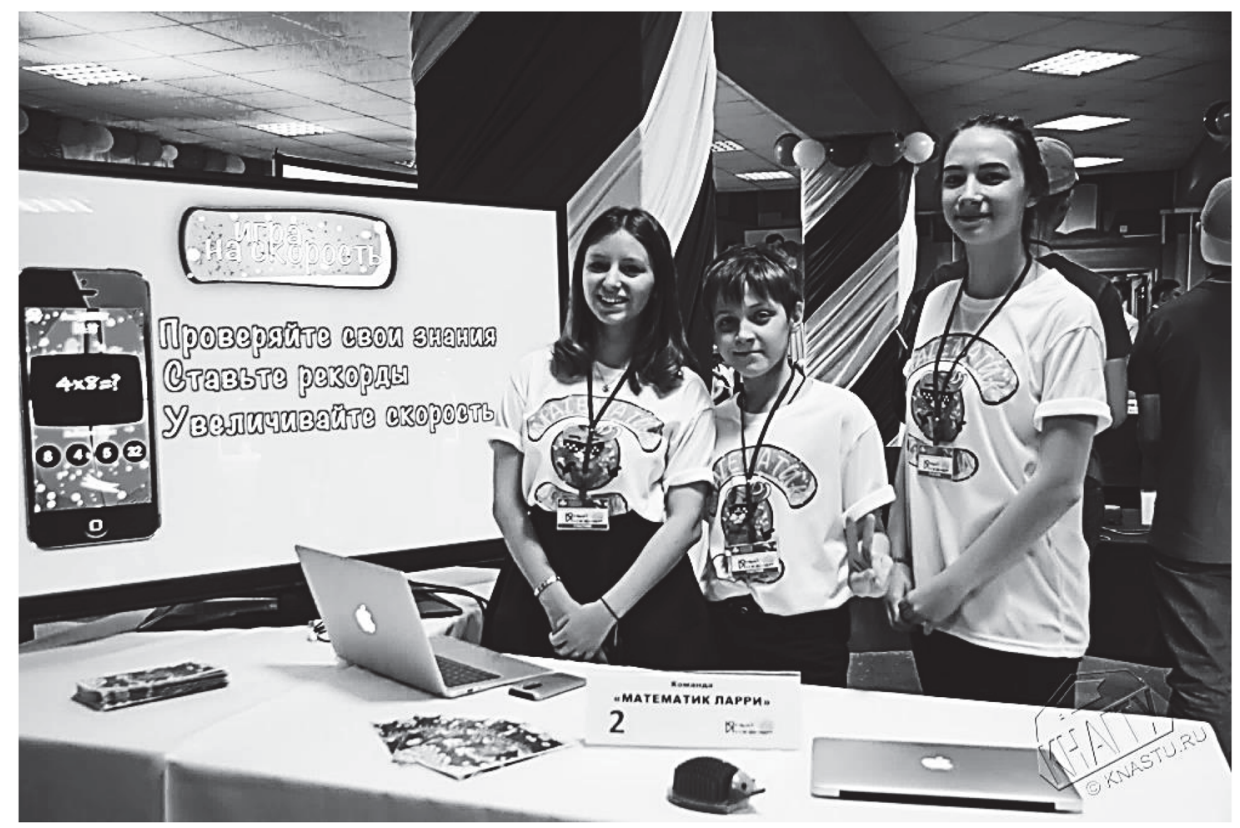

Рис. 4. Участники конкурса научно-технических проектов «Юный инженер»

В заключении отметим, что термин «ранняя профориентация» в свете государственных мер ранней профориентации часто используется для работ по профессиональному ориентированию школьников, в том числе старших классов. Мы считаем, что профориентирование учашихся школ лучше, по возможности, не откладывать до выпускных классов, а начинать проводить различные мероприятия, развивающие интерес к специальностям инженерной направленности, уже с начальной школы.

\section{ЛИТЕРАТУРА}

1. Прямая линия с Владимиром Путиным // Официальный сайт Президента России. - Режим доступа: http://kremlin.ru/events/president/news/49261.

2. «Технофест-2015» познакомил с инновационными разработками учёных КнАГТУ // Официальный сайт Комсомольского-на-Амуре государственного технического университета. - Режим доступа: https://knastu.ru/n/950.

3. Проект КнАГТУ - Каникулярная школа «Технологии будущего» победил в национальном конкурсе по профориентации школьников // Официальный сайт Комсомольского-на-Амуре государственного технического университета. - Режим доступа: https://knastu.ru/n/1524. 